\title{
Isolated mechanical aortic valve replacement in rheumatic patients in a low- to middle-income country
}

Jacques Scherman, MD, Rodgers Manganyi, MD, Paul Human, PhD, Timothy Pennel, MD, PhD,

Andre Brooks, MD, Johan Brink, MD, and Peter Zilla, MD, PhD

\section{ABSTRACT}

Objective: Although the results of aortic valve replacement are well documented for industrialized countries, the outcome in patients with rheumatic aortic valve disease in low- to middle-income countries is less well explored. The aim of this study was to determine the long-term survival and clinical outcomes after isolated aortic valve replacement in patients with rheumatic heart disease in a SubSaharan country where follow-up of indigent patients is often challenging.

Methods: A retrospective review of 969 aortic valve replacements performed between 2003 and 2013 was conducted at Cape Town's Groote Schuur Hospital. Patients who underwent concomitant procedures $(n=664)$ or had nonrheumatic valve pathology $(n=185)$ were excluded. The mean age of the rheumatic cohort $(\mathrm{n}=121)$ was $43.1 \pm 11.6$ years with a mean follow-up period of $6.14 \pm 3.44$ years. The primary end points were survival and valve-related complications.

Results: A 15\% cardiac- or valve-related 10-year mortality after receiving a mechanical prosthesis corresponded with a significantly higher mortality rate than that of a matched population. Overall cumulative survival at 1, 5, and 10 years was 93.5\% (87.0-96.9), 86.4\% (78.4-91.8), and 78.1\% (67.5-86.0), respectively, and the corresponding cumulative freedom from combined thromboembolism and bleeding was 94.4\% (88.2-97.5), 87.4\% (79.4-92.5), and 86.1\% (77.9-91.6), respectively.

Conclusions: In low- to middle-income countries, with their unique mix of indigent and "First World" patients, rheumatic heart disease still accounts for a significant proportion of patients requiring isolated aortic valve replacement. Although mechanical prostheses are often selected in these young adults, survival remains suboptimal. Major bleeding and thromboembolic events account for the majority $(77 \%)$ of the reported valve-related complications. (J Thorac Cardiovasc Surg 2019;157:886-93)

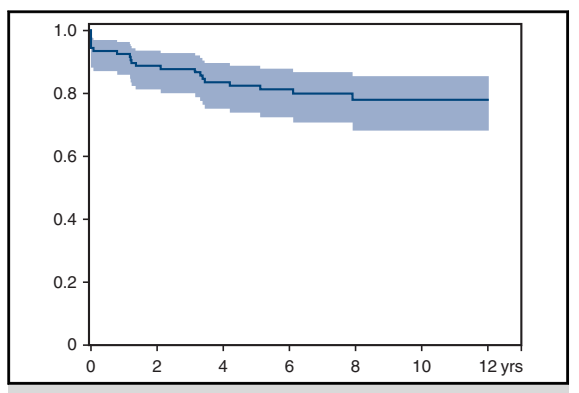

Freedom from major adverse valve-related events after mechanical AVR.

\section{Central Message}

In low- to middle-income countries, up to 1 of every 4 young rheumatic patients receiving a mechanical AVR have a major valve-related event within the first decade after valve replacement.

\section{Perspective}

None of the current heart valve prostheses offer a true lifelong solution. In young patients with RHD, compelling evidence is lacking to balance the risk of thromboembolic/bleeding events with mechanical valves against reoperative risk inherent to bioprostheses. Technological developments and evolving transcatheter solutions may together favor more liberal use of bioprostheses in these patients.

See Commentary on page 894.
In low- to middle-income countries, rheumatic heart disease (RHD) still accounts for the majority of patients in need of cardiac surgery. It is estimated that in Africa alone, there are

\footnotetext{
From the Chris Barnard Division of Cardiothoracic Surgery, University of Cape Town, Cape Town, South Africa.

Date and number of Institutional Review Board approval: May 28, 2014. HREC/REF: $344 / 2014$.

Received for publication March 25, 2018; revisions received May 29, 2018; accepted for publication June 15, 2018; available ahead of print Aug 11, 2018.

Address for reprints: Jacques Scherman, MD, Chris Barnard Division of Cardiothoracic Surgery, Groote Schuur Hospital, University of Cape Town, 7925 Observatory, Cape Town, South Africa (E-mail: jacques.scherman@uct.ac.za). $0022-5223 / \$ 36.00$

Copyright (c) 2018 by The American Association for Thoracic Surgery https://doi.org/10.1016/j.jtcvs.2018.06.083
}

15 million patients living with RHD, of whom 100,000 per year may need valve surgery during some stage of their lives, ${ }^{1}$ provided cardiac surgery is available. Because of the nature of the underlying disease, aortic valve repair options are limited, and as such, surgical aortic valve replacement (AVR) remains the treatment of choice for the majority of patients with symptomatic rheumatic aortic valve disease. Apart from access to open surgery, the choice of valve prosthesis presents a particular challenge given the socioeconomic circumstances of these patients. Yet, in the absence of local evidence-based recommendations, lowto middle-income countries largely apply First World guidelines when it comes to valve selection. ${ }^{2-4}$ As such, the majority of patients still receive mechanical valves at 


\section{Abbreviations and Acronyms}

$\mathrm{AVR}=$ aortic valve replacement

$\mathrm{INR}=$ international normalized ratio

RHD $=$ rheumatic heart disease

VIV $=$ valve-in-valve

a time when the collective experience of industrialized countries had long swung toward tissue valves because of their significantly older patient population. The de facto paradigm of this decision continues to be that the anticipation of premature tissue valve degeneration in young patients outweighs poverty-, culture-, and accessrelated adverse events associated with mechanical heart valves. Given this prevailing assumption, prospective comparative studies between the 2 valve types would be considered unethical, although the true outcome of mechanical valve replacements remains unknown. A first step toward evidence-based decision-making would be to determine the long-term fate of mechanical valve replacements in the largely young patients with rheumatic disease of a low- to middle-income country with reasonable access to cardiac surgery.

\section{MATERIALS AND METHODS}

The study was approved by the Institutional Review Board (Human Research Ethics Committee: Approval Ref 344/2014; Faculty of Health Sciences, University of Cape Town. Institutional Review Board: IRB00001938).

\section{Patients}

All patients who underwent an AVR at Cape Town's Groote Schuur Hospital between January 2003 and December 2013 were followed up retrospectively. A total of 969 patients were identified. Patients who underwent concomitant procedures, aortic root replacements, aortic valve repairs, transcatheter, or redo procedures were excluded $(n=664$ patients). We further excluded all patients who had underlying calcific degenerative disease, endocarditis, congenital aortic valve disease, or any other nonrheumatic heart valve pathology ( $\mathrm{n}=184$ patients), leaving 121 patients who underwent an isolated first-time AVR for RHD. The majority of these patients $(89 \%, \mathrm{n}=108)$ received a mechanical prosthesis. The subgroup of patients who received a bioprosthesis was small $(11 \%$, $\mathrm{n}=13$ ) and significantly older (mean age of $58.6 \pm 11.6$ years) than the mechanical group and therefore not included in the subsequent analysis. The preoperative baseline characteristics are summarized in Table 1. The mean age of this rheumatic cohort was $43.1 \pm 11.6$ years at the time of surgery, with $63.8 \%(n=69)$ of the cohort being male. Pure aortic regurgitation occurred in $61 \%$ of patients $(\mathrm{n}=66)$, pure aortic stenosis occurred in $8 \%$ of patients $(n=9)$, and $31 \%$ of patients $(n=33)$ had a mixed (predominantly regurgitant) aortic valve lesion. Atrial fibrillation was present in $8 \%$ of patients $(n=9)$ preoperatively. The majority of patients $(90 \%)$ presented in New York Heart Association class II or III at the time of surgery. The mean calculated Society of Thoracic Surgeons score (risk of mortality) of this rheumatic cohort was $0.7 \% \pm 0.2 \%$.
TABLE 1. Preoperative demographic characteristics of 108 rheumatic patients who underwent an isolated first-time mechanical aortic valve replacement

\begin{tabular}{|c|c|}
\hline Baseline characteristics & $\mathbf{N}(\%)$ \\
\hline Age, mean (SD), y & $43.1(11.6)$ \\
\hline Men & $69(63.8 \%)$ \\
\hline \multicolumn{2}{|l|}{ Race/ethnicity } \\
\hline Mixed race & $62(57.4 \%)$ \\
\hline Black & $41(34.2 \%)$ \\
\hline White & $4(3.7 \%)$ \\
\hline Indian & $3(2.8 \%)$ \\
\hline Asian & $2(1.9 \%)$ \\
\hline \multicolumn{2}{|l|}{ Cardiovascular risk factors/comorbidities } \\
\hline Hypertension & $25(23.1 \%)$ \\
\hline Diabetes & $7(6.5 \%)$ \\
\hline Dyslipidemia & $7(6.5 \%)$ \\
\hline Smoker & $14(12.9 \%)$ \\
\hline Atrial fibrillation & $9(8.3 \%)$ \\
\hline Immunocompromised (HIV positive) & $4(3.7 \%)$ \\
\hline \multicolumn{2}{|l|}{ New York Heart Association class } \\
\hline I & $7(6.5 \%)$ \\
\hline II & $59(54.6 \%)$ \\
\hline III & $38(35.2 \%)$ \\
\hline IV & $4(3.7 \%)$ \\
\hline \multicolumn{2}{|l|}{ Left ventricular ejection fraction } \\
\hline$<35 \%$ & $11(10.2 \%)$ \\
\hline $35 \%-49 \%$ & $30(27.8 \%)$ \\
\hline$\geq 50 \%$ & $67(62.0 \%)$ \\
\hline \multicolumn{2}{|l|}{ Aortic valve pathology } \\
\hline Regurgitation & $66(61.1 \%)$ \\
\hline Stenosis & $9(8.3 \%)$ \\
\hline Mixed disease & $33(30.6 \%)$ \\
\hline STS score (mortality), mean (SD) & $0.7(0.2)$ \\
\hline \multicolumn{2}{|l|}{ Level of education } \\
\hline Did not complete secondary school education & $91(84.3 \%)$ \\
\hline Completed secondary school education & $14(12.9 \%)$ \\
\hline Tertiary education & $3(2.8 \%)$ \\
\hline \multicolumn{2}{|l|}{ Employment status } \\
\hline Unemployed & $77(71.3 \%)$ \\
\hline Employed (temporary or permanent) & $28(25.9 \%)$ \\
\hline Social grant/retired & $3(2.8 \%)$ \\
\hline
\end{tabular}

$S D$, Standard deviation; HIV, human immunodeficiency virus; STS, Society of Thoracic Surgeons.

\section{Operative Data and Prosthesis Selection}

The mean cardiopulmonary bypass time was $114 \pm 26$ minutes with a crossclamp time of $78 \pm 21$ minutes. All procedures were performed under moderate hypothermia using St Thomas crystalloid cardioplegic solution. The distribution of mechanical prostheses was as follows: St Jude Medical (Saint Paul, Minn) in 32 patients (26\%), On-X (CryoLife Inc, Kennesaw, Ga) in 30 patients $(25 \%)$, Edwards MIRA (Edwards Lifesciences Inc, Irvine, Calif) in 23 patients (19\%), Medtronic Advantage (Medtronic Inc, Minneapolis, Minn) in 19 patients (16\%), and Medtronic ATS (Medtronic Inc) in 4 patients $(3 \%)$. 


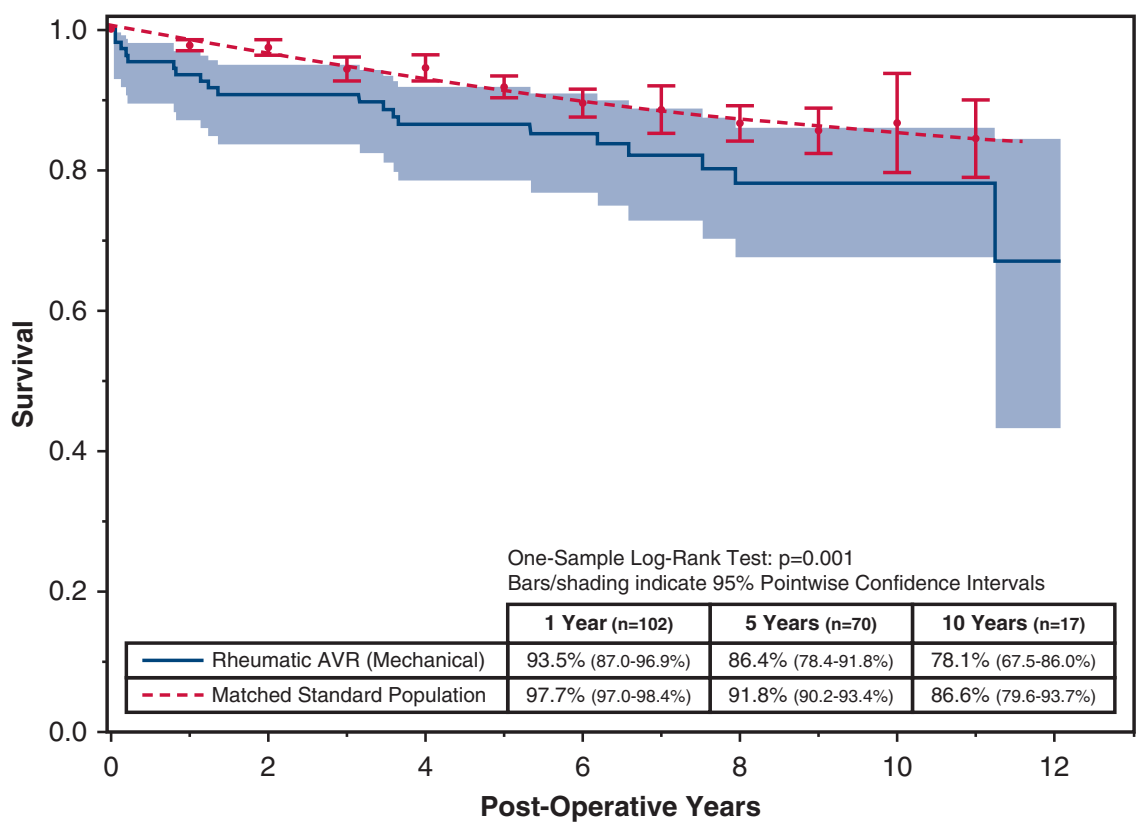

FIGURE 1. Survival in a rheumatic cohort of patients who underwent isolated mechanical AVR, compared with a sex- and age-matched population in the Western Cape, South Africa. AVR, Aortic valve replacement.

\section{Anticoagulation and Postoperative Management}

Anticoagulation therapy with warfarin was routinely commenced on the first postoperative day in all patients who received a mechanical prosthesis. A low-molecular-weight heparin was concomitantly used until a target international normalized ratio (INR) between 2 and 3 was reached. After discharge from the hospital, all patients were referred to their closest medical clinic or facility where further INR testing and follow-up could be performed.

\section{Data Collection and Outcomes}

During the past decade, the widespread use of prepaid mobile phones, as well as institutional and national laboratory databases, introduced improved means for follow-up, thus far unavailable, for a patient population with a significant rural component.

Data were retrospectively collected using the cardiac surgical database of the Chris Barnard Division of Cardiothoracic Surgery, University of Cape Town, as well as from hospital medical records, the metropolitan hospital-link database, the National Health Laboratory Service's database, and telephone interviews.

The follow-up period ended in October 2014. The mean follow-up period was $6.1 \pm 3.4$ years and $100 \%$ complete. The primary outcomes were valve-related mortality and valve-related morbidity, which included prosthetic valve dysfunction, bleeding and embolic events, prosthetic valve endocarditis, and the need for reintervention. The outcomes were reported as per guidelines for reporting mortality and morbidity after cardiac valve interventions. ${ }^{5}$

\section{Statistical Analysis}

Statistical analysis was performed using the JMP statistical software package (version 10.0.2, SAS Institute Inc, Cary, NC). All continuous numeric data were expressed as means \pm standard deviation. KaplanMeier survival estimates were expressed as percentages and $95 \%$ confidence intervals. For comparison of mortality rates with that of the standard population, the method described by Finkelstein and colleagues, ${ }^{6}$ using age- and sex-matched vital data, obtained for the Western Cape Province from Statistics South Africa, was used. ${ }^{6}$ Statistical comparison between standard population and cohort patient survival was performed using the 1 -sample log-rank test. For visual comparison, $95 \%$ pointwise confidence intervals were included.

\section{RESULTS}

The main finding of this retrospective analysis was a significantly inferior long-term survival of the study group compared with an age- and sex-matched comparable South African subpopulation (Figure 1) with 39\% $(\mathrm{n}=7)$ of late deaths being valve related. Major bleeding and thromboembolic events ( $\mathrm{n}=17$ events) accounted for the majority $(77 \%)$ of the reported valve-related complications. One of every 4 of these young rheumatic patients had a major adverse valve-related event (mortality or major morbidity) during the first decade after having received a mechanical aortic valve prosthesis.

\section{Early Mortality and Complications}

The in-hospital/30-day mortality for the rheumatic mechanical AVR cohort was $1.9 \%(n=2)$. The causes of early death were multiorgan failure $(\mathrm{n}=1)$ and a thromboembolic neurologic event $(\mathrm{n}=1)$. New-onset atrial fibrillation/flutter occurred in $4.6 \%(\mathrm{n}=5)$ of patients. New-onset atrioventricular block requiring a permanent pacemaker occurred in $1.9 \%(\mathrm{n}=2)$. Bleeding requiring reoperation ( $<48$ hours) occurred in $2.8 \%(\mathrm{n}=3)$, late drainage of a pericardial effusion ( $<30$ days) occurred in $1.9 \%(\mathrm{n}=2)$, renal failure occurred in $0.9 \%(\mathrm{n}=1)$, and early stroke occurred in $0.9 \%(\mathrm{n}=1)$ of patients. 
TABLE 2. Late mortalities

\begin{tabular}{lc}
\hline & $\begin{array}{c}\text { Mechanical AVR prosthesis } \\
(\mathbf{n}=\mathbf{1 0 6} \text { patients })\end{array}$ \\
\hline Total all-cause late mortalities & $\mathrm{N}=18(17.0 \%)$ \\
Valve related & $\mathrm{n}=7(38.9 \%)$ \\
Endocarditis & 1 \\
Thromboembolism & 1 \\
Bleeding event & 1 \\
Reoperation & 2 \\
Sudden unexplained & 2 \\
Other cardiac related & $\mathrm{n}=9(50.0 \%)$ \\
Congestive cardiac failure & 9 \\
Acute myocardial infarction & 0 \\
Arrhythmias & 0 \\
Noncardiac & $\mathrm{n}=2(11.1 \%)$ \\
\hline
\end{tabular}

AVR, Aortic valve replacement.

\section{Late Mortality}

Late mortality (all cause) occurred in 18 of 106 patients $(17 \%)$ at a mean of $43 \pm 37$ months after surgery. The majority of the late deaths were cardiac or valve related $(89 \%$, $\mathrm{n}=16$ ). Table 2 summarizes the causes of late deaths. $\mathrm{Cu}-$ mulative survival at 1,5 , and 10 years after mechanical AVR was 93.5\% (87.0-96.9), 86.4\% (78.4-91.8), and $78.1 \%(67.5-86.0)$, respectively. This was considerably lower than that of the age- and sex-matched population in the Western Cape Province, South Africa, where this study was conducted, whose expected survival was $97.7 \%$ (97.098.4), 91.8\% (90.2-93.4), and 86.6\% (79.6-93.7), respectively $(P<.001)$ (Figure 1$)$.

\section{Valve-Related Morbidity}

Overall, 9 major bleeding and 8 thromboembolic events occurred in 14 patients. Of the thromboembolic events, 7 were strokes and 1 was a transient ischemic event. The cumulative freedom from the composite of thromboembolism and bleeding after mechanical AVR was $94.4 \%$ (88.2-97.5), $87.4 \%(79.4-92.5)$, and $86.1 \%(77.9-91.6)$ at 1,5 , and 10 years, respectively (Figure 2).

Only 2 reoperations were performed during the follow-up period ( $6.14 \pm 3.44$ years). The indications for reintervention were valve thrombosis $(\mathrm{n}=1)$ and prosthetic valve endocarditis $(\mathrm{n}=1)$. As such, freedom from reoperation at 1 , 5, and 10 years was $100 \%, 99.0 \%$ (93.0-99.9), and 96.9\% (87.4-99.3), respectively.

Freedom from any valve-related event (ie, prosthetic valve dysfunction, bleeding/thromboembolic events, prosthetic valve endocarditis, and the need for reintervention) at 1,5 , and 10 years was $94.4 \%$ (88.2-97.5), 87.4\% (79.4-92.5), and 82.9\% (73.5-89.4), respectively (Figure 3).

\section{Major Adverse Valve-Related Events}

Freedom from major adverse valve-related events (ie, valve-related mortality, valve-related morbidity, and the need for a new pacemaker) at 1,5 , and 10 years was $92.6 \%$ (85.9-96.3), 82.6\% (74.0-88.8), and 78.1\% (68.485.5), respectively (Figure 4). A further subanalysis comparing the different types of mechanical prosthesis used did not show any significant difference in terms of major adverse valve-related events $(P=.23)$.

\section{DISCUSSION}

With the often remarkable growth of cardiac surgery in emerging economies in which RHD still prevails, the reliance on First World guidelines for the choice of replacement valves that do not take the specific pathology, patient age, and socioeconomic circumstances of the affected patients into account may result in unintended poor outcomes.

Our cohort analysis of single mechanical AVRs in rheumatic patients showed a significantly higher 10-year mortality than their matched population counterparts. This sobering outcome was aggravated by the fact that the mean age of these patients was less than 45 years. Together with low mortality rates for reoperations for degenerated tissue valves, ${ }^{7-9}$ a $15 \%$ ten-year cardiac- or valve-related mortality after receiving a mechanical valve prosthesis justifies a critical appraisal of our current practice of prosthesis selection.

Recent renewed interest in RHD and the increasing volumes of cardiac operations performed in the affected countries have led to a shift in focus from merely emulating First World standards toward recognition of the need to respond to a distinctly different pathology, resource, and patient baseline. $^{1,10}$ Epidemiologic assessments of disease burdens countering the widely held belief that RHD has been largely contained need to form the backbone of such a reorientation. Validating this quest, Sliwa and colleagues ${ }^{11}$ found the incidence of RHD in South African patients aged 14 years or more as high as 24 per 100,000 per year, a stark contrast to the less than 1 of 100,000 in developed countries. ${ }^{12}$ More important, within 30 months of diagnosis, $22 \%$ of these newly diagnosed patients needed heart valve surgery. ${ }^{11}$

\section{Challenges in Dealing With Patients With Rheumatic Heart Disease}

In the relatively young patients with RHD, compelling evidence is still lacking to balance the risk of anticoagulation-related bleeding and thromboembolism associated with a mechanical valve with the risk of structural valve deterioration and potential reoperation inherent to bioprostheses. ${ }^{13}$ Yet, observational studies have shown that major bleeding and thromboembolic complications in patients with mechanical valves are generally higher in low- to middle-income countries than in high-income countries. ${ }^{14}$ In the present study, the majority of patients did not complete secondary school education $(84 \%)$ and $71 \%$ were 


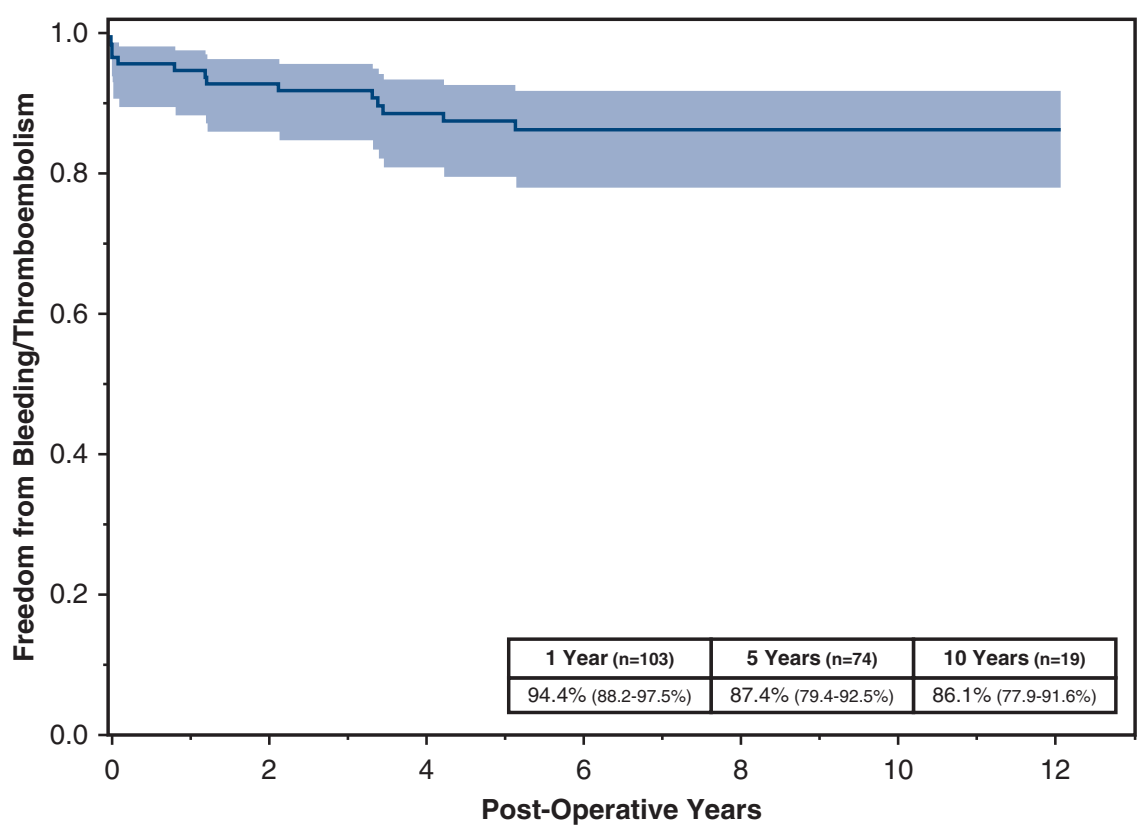

FIGURE 2. Freedom from major bleeding and thromboembolic events in a rheumatic cohort of patients who underwent isolated mechanical AVR.

unemployed. Infrastructure such as transportation and access to health facilities in low- to middle-income countries is often suboptimal for ensuring therapeutic anticoagulation. ${ }^{15}$ In the current series, major bleeding and thromboembolic events accounted for the majority $(77 \%, \mathrm{n}=17)$ of the reported valve-related complications.

Although the rate of structural valve degeneration of bioprostheses is inversely proportional to a patient's age, ${ }^{16}$ prosthesis durability, a patient's life expectancy, operative risk of a redo procedure, and the socioeconomic circumstances of typical rheumatic populations must be interpreted together. Even in industrialized countries, the life expectancy of patients who underwent an AVR is substantially lower than that of the general population. ${ }^{17,18}$ In a large contemporary First World series, Bouhout and colleagues ${ }^{19}$ also reported suboptimal survival in young patients receiving mechanical prostheses. Of note is their higher cumulative survival at 1,5 , and 10 years of $98 \% \pm 1 \%, 95 \% \pm 1 \%$, and $87 \% \pm 1 \%$, respectively, despite an older mean age of $53 \pm 9$ years compared with $43.1 \pm 11.6$ years in our series. ${ }^{19}$ Therefore, weighing the risk of anticoagulation-related events versus prosthesis longevity needs to be interpreted in the context of the even lower life expectancy of AVR recipients in low- to middle-income countries. Thus, when several large series reported the operative mortality risk for reoperative AVR cases to be $5 \%$ to $7 \%,{ }^{7-9}$ this relatively low risk must be compared with the lifetime risk of anticoagulation-related events in the poorly anticoagulated communities of developing countries. During the follow-up in a Kenyan series, for instance, only $7 \%$ of mechanical valve recipients had adequate anticoagulation for more than $50 \%$ of the 5 -year observation period. ${ }^{20}$

Cardiac disease in pregnancy is associated with high morbidity and mortality rates. ${ }^{1,21}$ RHD is the most common underlying cardiac lesion in pregnant patients presenting at referral hospitals in South Africa, and as such the incidence of AVRs in this age group is also higher than in developed countries. ${ }^{22}$ Although the patient's young age would qualify them for a mechanical valve, the detrimental effects of warfarin during the first and last trimesters of pregnancy have been well described. Our study underlined the magnitude of this most distinctive difference in patient populations: More than one third $(36.2 \%)$ of our rheumatic patients with mechanical AVR were female (mean age, $44.3 \pm 11.5$ years), and a significant proportion presented during their childbearing years or even during pregnancy.

\section{Alternative Solutions for Low- to Middle-Income Countries}

The use of new anticoagulants, such as direct thrombin inhibitors, is particularly attractive and shown to be an effective alternative to warfarin in patients with atrial fibrillation. However, its use in patients with mechanical heart valves has been associated with increased rates of thromboembolic and bleeding complications. ${ }^{23}$ In view of this excess risk, warfarin remains the drug of choice in patients with mechanical prostheses, until new evidence becomes available.

Genotype-based warfarin dosing has shown some promise during the initiation phase of warfarin therapy. ${ }^{24}$ 


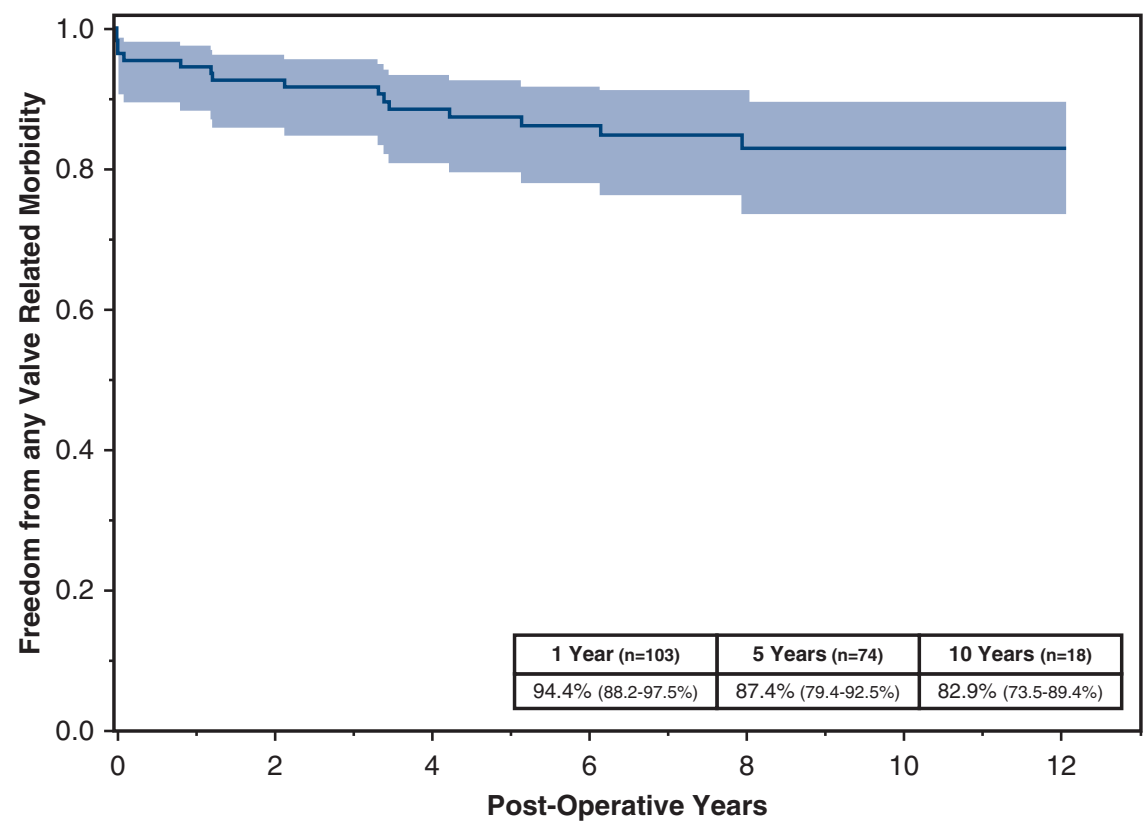

FIGURE 3. Freedom from any valve-related complication (including prosthetic valve dysfunction, bleeding and thromboembolic events, prosthetic valve endocarditis, and the need for reintervention) in a rheumatic cohort of patients who underwent isolated mechanical AVR.

However, these trials have been limited to patients with European ethnic and socioeconomic backgrounds and provide no guidance on long-term anticoagulation management in our environment.

The recent results from the PROACT trial are encouraging in that INR levels after mechanical AVR with the On-X prosthesis can be safely maintained at lower levels (1.5 to 2.0 ), without increased risk of anticoagulation- related events. ${ }^{25}$ However, this strategy still requires the use of warfarin with careful monitoring (including homebased monitoring) and is better suited for selected patients only. Furthermore, the results from this study only demonstrated a reduction in the rate of major bleeding events, but a higher number of thromboembolic events.

Transcatheter valve-in-valve (VIV) procedures are also of potential interest in this setting. ${ }^{26}$ Results of

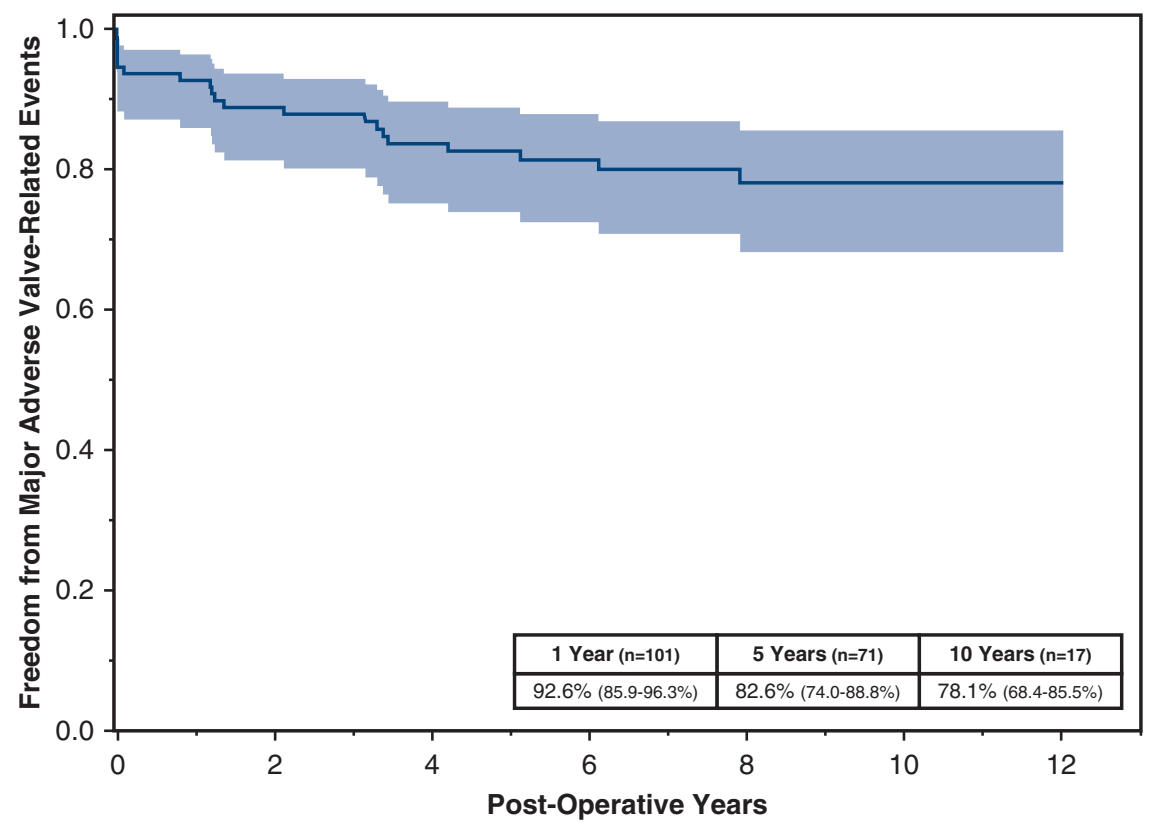

FIGURE 4. Freedom from major adverse valve-related events in a rheumatic cohort of patients who underwent isolated mechanical AVR. 
perioperative outcomes from global VIV registries are encouraging, but the paucity of information about the long-term durability of aortic VIV procedures warrants further investigations. ${ }^{27}$

\section{Study Limitations}

This study is observational, and data were collected retrospectively.

\section{CONCLUSIONS}

In low- to middle-income countries, RHD still accounts for the major burden of disease in patients needing heart valve interventions. None of the current heart valve prostheses offer a lifelong solution. Given that, (1) the life expectancy after an AVR (with either prosthesis), particularly in younger patients with RHD, is substantially lower than the life expectancy of the general population; (2) warfarin compliance and INR control are suboptimal in developing countries; (3) the incidence of major bleeding and thromboembolic complications is significantly higher in developing countries; and (4) a significant part of rheumatic patients present during their childbearing years; thus, a substantial number of young rheumatic patients living in low- to middle-income countries may be exposed to a lower lifetime risk of experiencing a valve-related event by selecting a bioprosthetic heart valve from the outset. Despite the relative increased mortality risk associated with reoperations for degenerated bioprostheses, new technological developments that may increase the longevity of soft-leaflet prostheses $^{28,29}$ and evolving transcatheter solutions for lowincome countries that may broaden the access of patients to heart valve replacements ${ }^{30}$ may together favor a more liberal use of bioprosthetic valves in young patients with RHD.

\section{Conflict of Interest Statement}

Authors have nothing to disclose with regard to commercial support.

The authors thank Benjamin Landon Myer from the Division of Epidemiology and Biostatistics in the School of Public Health and Family Medicine at the University of Cape Town, South Africa, for consultation and statistical support.

\section{References}

1. Sliwa K, Zilla P. Rheumatic heart disease: the tip of the iceberg. Circulation. 2012;125:3060-2.

2. Vahanian A, Alfieri O, Andreotti F, Antunes MJ, Baron-Esquivias G, Baumgartner $\mathrm{H}$, et al. Guidelines on the management of valvular heart disease (version 2012): the Joint task force on the management of valvular heart disease of the European Society of Cardiology (ESC) and the European Association for Cardio-Thoracic Surgery (EACTS). Eur J Cardiothorac Surg. 2012;42:S1-44.

3. Nishimura RA, Otto CM, Bonow RO, Carabello BA, Erwin JP III, Guyton RA, et al. 2014 AHA/ACC guideline for the management of patients with valvular heart disease: a report of the American College of Cardiology/American Heart Association task force on practice guidelines. J Thorac Cardiovasc Surg. 2014; 148:e1-132.
4. Hammermeister K, Sethi GK, Henderson WG, Grover FL, Oprian C, Rahimtoola SH. Outcomes 15 years after valve replacement with a mechanical versus a bioprosthetic valve: final report of the veterans affairs randomized trial. J Am Coll Cardiol. 2000;36:1152-8.

5. Akins CW, Miller DC, Turina MI, Kouchoukos NT, Blackstone EH, Grunkemeier GL, et al. Guidelines for reporting mortality and morbidity after cardiac valve interventions. J Thorac Cardiovasc Surg. 2008;135:732-8.

6. Finkelstein DM, Muzikansky A, Schoenfeld DA. Comparing survival of a sample to that of a standard population. J Natl Cancer Inst. 2003;95:1434-9.

7. Jamieson WR, Burr LH, Miyagishima RT, Janusz MT, Fradet GJ, Ling H, et al. Re-operation for bioprosthetic aortic structural failure - risk assessment. Eur J Cardiothorac Surg. 2003;24:873-8.

8. Potter DD, Sundt TM III, Zehr KJ, Dearani JA, Daly RC, Mullany CJ, et al. Operative risk of reoperative aortic valve replacement. J Thorac Cardiovasc Surg. 2005; 129:94-103.

9. LaPar DJ, Yang Z, Stukenborg GJ, Peeler BB, Kern JA, Kron IL, et al. Outcomes of reoperative aortic valve replacement after previous sternotomy. J Thorac Cardiovasc Surg. 2010;139:263-72.

10. Zühlke L, Engel ME, Karthikeyan G, Rangarajan S, Mackie P, Cupido B, et al. Characteristics, complications, and gaps in evidence-based interventions in rheumatic heart disease: the global rheumatic heart disease registry (the REMEDY study). Eur Heart J. 2015;36:1115-1122a.

11. Sliwa K, Carrington M, Mayosi BM, Zigiriadis E, Mvungi R, Stewart S. Incidence and characteristics of newly diagnosed rheumatic heart disease in urban African adults: insights from the heart of Soweto study. Eur Heart J. 2010;31:719-27.

12. Tibazarwa KB, Volmink JA, Mayosi BM. Incidence of acute rheumatic fever in the world: a systematic review of population-based studies. Heart. 2008;94:1534.

13. Choudhary SK, Talwar S, Airan B. Choice of prosthetic heart valve in a developing country. Heart Asia. 2016;8:65-72.

14. Sun JCJ, Davidson MJ, Lamy A, Eikelboom JW. Antithrombotic management of patients with prosthetic heart valves: current evidence and future trends. Lancet. 2009;374:565-76.

15. Williams MA, Crause L, Van Riet S. A comparison of mechanical valve performance in a poorly anticoagulated community. J Card Surg. 2004;19:410-4.

16. Glaser N, Jackson V, Holzmann MJ, Franco-Cereceda A, Sartipy U. Aortic valve replacement with mechanical vs. biological prostheses in patients aged 50-69 years. Eur Heart J. 2016;37:2658-67.

17. Kvidal P, Bergstrom R, Horte LG, Stahle E. Observed and relative survival after aortic valve replacement. J Am Coll Cardiol. 2000;35:747-56.

18. Van Geldorp MWA, Jamieson WRE, Kappetein AP, Ye J, Fradet GJ, Eijkemans MJC, et al. Patient outcome after aortic valve replacement with a mechanical or biological prosthesis: weighing lifetime anticoagulant-related event risk against reoperation risk. J Thorac Cardiovasc Surg. 2009;137:881-6.

19. Bouhout I, Stevens LM, Mazine A, Poirier N, Cartier R, Demers P, et al. Longterm outcomes after elective isolated mechanical aortic valve replacement in young adults. J Thorac Cardiovasc Surg. 2014;148:1341-6.

20. Ogendo SW. Long term valve-related morbidity following open-heart surgery at the Kenyatta National Hospital. East Afr Med J. 2000;77:199-202.

21. Sliwa K, Johnson MR, Zilla P, Roos-Hesselink JW. Management of valvular disease in pregnancy: a global perspective. Eur Heart J. 2015;36:1078-89.

22. Soma-Pillay P, Macdonald AP, Mathivha TM, Bakker JL, Mackintosh MO. Cardiac disease in pregnancy: a 4-year audit at Pretoria Academic Hospital. S Afr Med J. 2008:98:553-6.

23. Eikelboom J, Connolly SJ, Brueckmann M, Granger CB, Kappetein AP, Mack MJ, et al. Dabigatran versus warfarin in patients with mechanical heart valves. $N$ Engl J Med. 2013;369:1206-14.

24. Pirmohamed M, Burnside G, Eriksson N, Jorgensen AL, Toh CH, Nicholson T, et al. A randomized trial of genotype-guided dosing of warfarin. $N$ Engl $J$ Med. 2013;369:2294-303.

25. Puskas J, Gerdisch M, Nichols D, Quinn R, Anderson C, Rhenman B, et al; on behalf of all PROACT Investigators. Reduced anticoagulation after mechanical aortic valve replacement: interim results from the prospective randomized on$\mathrm{X}$ valve anticoagulation clinical trial randomized food and drug administration investigational device exemption trial. J Thorac Cardiovasc Surg. 2014;147: 1202-10.

26. Gurvitch R, Cheung A, Ye J, Wood DA, Willson AB, Toggweiler S, et al. Transcatheter valve-in-valve implantation for failed surgical bioprosthetic valves. JAm Coll Cardiol. 2011:58:2196-209.

27. Dvir D, Webb J, Brecker S, Bleiziffer S, Hildick-Smith D, Colombo, et al. Transcatheter aortic valve replacement for degenerative bioprosthetic surgical valves: result from the global valve-in-valve registry. Circulation. 2012;126:2335-44. 
28. Bezuidenhout D, Oosthuysen A, Weissenstein C, Human P, Zilla P. Effects of crosslinking density and chemistry on the calcification potential in diamineextended glutaraldehyde-fixed bioprosthestic heart-valve materials. Biotechnol Appl Biochem. 2009;54:133-40.

29. Zilla P, Brink J, Human P, Bezuidenhout D. Prosthetic heart valves: catering for the few. Biomaterials. 2008:29:385-406.
30. Scherman J, Bezuidenhout D, Ofoegbu C, Williams DF, Zilla P. TAVI for low to middle income countries. Eur Heart J. 2017;38:1182-4.

Key Words: aortic valve replacement, rheumatic heart disease, surgery in low- to middle-income countries 